\title{
LA CENTROIZQUIERDA PARECE NO COMPRENDER EL CHILE ACTUAL*
}

\author{
Carlos Vergara
}

Flacso

\begin{abstract}
RESUMEN: El autor postula que para entender la situación actual de la centroizquierda en Chile es necesario mirar la segunda mitad del siglo XX. Allí se hallan las claves de su interpretación del mundo y de su anclaje en dilemas del pasado, que no leen hoy correctamente la sociedad que ella misma contribuyó a crear.

Palabras Clave: Concertación, transición chilena, socialdemocracia, centroizquierda, Estado, mercado, bienes públicos.
\end{abstract}

\section{THE CENTRE-LEFT SEEMS NOT TO UNDERSTAND TODAY'S CHILE}

ABSTRACT: The author argues that it is necessary to look at the second half of the twentieth century to understand the current situation of the Chilean centre-left. That period provides the clues to its interpretation of the world and absorption in dilemmas of the past that do not accurately reflect today the society it itself helped to create.

KEYwords: Concertación, Chilean transition, social democracy, centre-left, State, market, public goods.

Carlos Vergara. Sociólogo de la Pontificia Universidad Católica de Chile. Director de estudios del Ministerio de la Secretaría General de la Presidencia (1994-2000). Asesor principal de análisis estratégico de la Presidencia de la República (20002006). Actualmente es investigador de Flacso. Email: carlosvergar@gmail.com.

* Versión revisada de la conferencia presentada en el Centro de Estudios Públicos el miércoles 27 de junio de 2018, con ocasión de la primera parte del seminario "La centroizquierda en Chile. ¿Cómo se llegó a esto? ¿Cómo se sale?”. 
ara entender mejor qué pasó con la centroizquierda en Chile, es necesario hacer una breve descripción de ciertos parámetros históricos e ideológicos de la segunda mitad del siglo XX, particularmente del último tercio.

\section{UNA LECTURA DEL SIGLO XX}

La historia de la segunda mitad del siglo XX en Europa pareciera estar gobernada por la pugna entre dos grandes valores: la libertad y la igualdad. La lucha entre estos dos valores configura la escenografía de lo que se ha llamado la Guerra Fría: la relación entre la URSS y los Estados Unidos, su voluntad por generar áreas de dominación en el mundo, por imponer sus modos de pensar y gobernar. Ello se traducía en una noción de libertad cada vez más entendida como libertad económica (fomento del capitalismo) y en una noción de igualdad entendida como la lucha de los pobres contra los poderosos (anticapitalismo). Dicha tensión toma la forma, en muchas partes, de la pugna entre izquierda y derecha, que en términos de gobierno y políticas públicas se traduce en una pugna de Estado versus mercado.

Los unos, partidarios de la construcción del socialismo, fueron fervientes promotores de la igualdad (o, si se prefiere, de terminar con la desigualdad), anticapitalistas y partidarios de la planificación de la economía desde el Estado.

Los otros, partidarios del capitalismo, fueron defensores de la "libertad" básicamente económica (a la hora de terminar con las libertades personales y políticas no dudaron en hacerlo) y entusiastas del mercado como el gran mecanismo de asignación de recursos y crecimiento de la economía.

La socialdemocracia europea nacida en la frontera del mundo de la URSS pareció ser la gran excepción a este esquema general.

\section{ENTRANDO AL CHILE DEL TERCER TERCIO DEL SIGLO XX}

Chile era, políticamente hablando, un país de tres tercios: una derecha clásica liberal-conservadora, un centro tomado por el socialcristianismo ("revolución en libertad") y una izquierda buscando la construcción del socialismo. A este respecto, cabe llamar la atención acerca de 
la enorme influencia, a partir de los años sesenta, que tuvo la revolución cubana en la juventud de izquierda de esa época, lo cual hacía que una parte importante de la juventud de la época, particularmente estudiantes universitarios, en su ideal de construir una sociedad más justa, se identificara con el liderazgo de Fidel Castro y el Che Guevara.

Cabe recordar que en las elecciones presidenciales de 1964 gana el candidato de centro, del Partido Demócrata Cristiano (PDC), apoyado por la derecha. En las elecciones presidenciales de 1970, gana el candidato de la izquierda, Salvador Allende, con el 35 por ciento de los votos. Es el primer gobierno socialista en el mundo en ser electo por votación democrática, pero el centro político — el PDC - se va alineando crecientemente con la derecha, hasta terminar con el golpe militar de 1973.

La dictadura acaba con la democracia, con las libertades básicas, viola los derechos humanos, gobierna con altos índices de pobreza y es respaldada a todo evento por la derecha social y política chilena.

Terminar con la dictadura abre el campo y la posibilidad para la creación y la existencia de una alianza de centroizquierda, básicamente la alianza entre el PDC y el Partido Socialista (PS).

\section{LA CONCERTACIÓN: ALIANZA DE CENTROIZQUIERDA}

Esta alianza de centroizquierda, entre el PDC y el PS — de la que no participan el Partido Comunista (PC) ni el Movimiento de Izquierda Revolucionaria (MIR) — , es inédita, pero logra terminar pacíficamente con la dictadura al ganar el plebiscito de 1988. Con el nombre de Concertación de Partidos por la Democracia, luego se organiza para dar un gobierno democrático y progresista a Chile.

La Concertación, al iniciar su gobierno, se propone tres objetivos fundamentales:

i) Recuperar y restaurar el pleno funcionamiento de las instituciones de la democracia y las libertades públicas, y reinstalar el más absoluto respeto por los derechos humanos.

ii) Disminuir radicalmente los niveles de pobreza del país.

iii) Generar crecimiento económico en beneficio de toda la sociedad.

Si uno analiza lo ocurrido en Chile entre 1990 y 2018 -cuando a los veinte años de gobierno de la Concertación se suman dos gobiernos 
que, en términos generales, continuaron su obra- $\mathrm{y}$ tomando en consideración los objetivos señalados, podemos observar que:

i) La democracia fue re-instalada, se ha ido perfeccionando, y los derechos humanos son universalmente respetados.

ii) El nivel de pobreza en Chile bajó de un nivel de 40 por ciento a un nivel que hoy bordea el 10 por ciento. Para esta cantidad de tiempo, es la reducción de pobreza más grande no sólo de América Latina, sino que del mundo entero.

iii) La cantidad de alumnos en educación superior pasó de un orden de 120 mil alumnos a un orden de 1.200 .000 alumnos; vale decir, se multiplican por diez. Cabe consignar que, hacia mediados de los años 2000 , cerca del 70 por ciento de los estudiantes en educación superior estaba compuesto por la primera generación - de sus familiasque accedía a la universidad.

iv) El PIB per cápita pasó de los 5 mil dólares a los 23 mil dólares; o sea, se multiplicó casi por cinco veces. Es también, y por lejos, el crecimiento más alto de toda América Latina en este período.

\section{4. ¿QUÉ PASÓ?}

Todo lo anterior significa un cambio radical y gigantesco de la sociedad chilena. Un tercio de la población pasa de la pobreza a ser clase media, y, si bien aún mantienen grados de vulnerabilidad, sus hijos estudian en la universidad, y tienen acceso al consumo y al crédito como nunca antes en sus vidas.

Esta nueva clase media tiene como aspiración principal el acceso a bienes públicos de calidad para todos los ciudadanos. Educación, salud, pensiones y, por cierto, empleo y remuneraciones constituyen el objetivo social al cual aspiran.

Al mismo tiempo, el pánico metafísico de esa clase media emergente y vulnerable es volver a la pobreza.

Este cambio radical de la sociedad chilena se produce, además, en el contexto de cambios radicales del mundo moderno: la revolución digital, los problemas del cambio climático, la crisis de la globalización y de la socialdemocracia europea.

El problema principal de la centroizquierda en Chile, entonces, es que su dirigencia política no supo leer correctamente esos cambios. La 
sociedad dejó de ser la simple división entre empresarios y obreros; los pobres ya no son una inmensa mayoría; se abrieron las puertas de las universidades, del consumo, del crédito, de la casa propia y de la movilidad social.

\section{EL RETORNO DE LOS DILEMAS ANTIGUOS}

La incapacidad de leer correctamente la nueva sociedad chilena hace reflotar las viejas contradicciones de los años sesenta: igualdad versus libertad económica; Estado versus mercado; derechos versus lucro. Pero es necesario hacer una nueva lectura de tales contradicciones. El problema de la centroizquierda en Chile, entonces, es que no ha logrado hacerlo; no ha desarrollado una nueva lectura de la sociedad chilena.

La reforma educacional es un ejemplo claro: más allá de la controvertida metáfora de los patines del ministro Nicolás Eyzaguirre, dirigentes del Frente Amplio no han dudado en repetir que el objetivo de la reforma propiciada por el segundo gobierno de Michelle Bachelet era sacar a la educación de la esfera del mercado (o sea, terminar con la educación subvencionada). Para ellos, la nueva sociedad debe estar basada en derechos, y éstos —educación, salud, pensiones - no deben estar ligados al mercado. O sea, Estado y no mercado.

Y si la izquierda se aferra al Estado, cuando se lee a algunos intelectuales y políticos de la derecha, se ve que ellos marchan por el camino contrario: defender la libertad económica de las personas; defender la idea de que pagar por un derecho es lo único que garantiza calidad y, por tanto, todos los derechos dependen de lo que diga el mercado.

No es que el Estado y el mercado sean ideas del pasado. Pero irse enteramente para un lado o para el otro sí es del pasado, es el eje de la guerra fría. El problema es definir, para las políticas públicas, cuál es la relación justa y adecuada entre Estado y mercado. Y es claro que esa relación no puede ser la misma de los años cincuenta ni de los años noventa. Se recuperó la democracia, se superó más que significativamente la pobreza, se ha conquistado una sólida base para enfrentar los desafíos del crecimiento económico.

Para la centroizquierda, el tema de la igualdad no puede ser el único tema. Hay otros, como la generación de bienes públicos de alta cali- 
dad para todos, la inclusión social, dignidad para todos, fin de los abusos, hacer frente a los temas del cambio climático, del medio ambiente, de los derechos de la mujer.

Y el tema de la desigualdad social hoy no es sólo un asunto de diferencias de ingresos, que por cierto las hay, sino que debe incluir también las desigualdades territoriales: por ejemplo, en Santiago, las diferencias entre las comunas respecto a la cantidad de metros cuadrados de áreas verdes por familia, las facilidades de transporte, el acceso a farmacias, y así por delante.

Son inimaginables, hoy y en el futuro próximo, las políticas públicas de desarrollo del país, de inclusión social, de generación de bienes públicos de calidad para todos, en las que no exista el mercado y, mucho menos, en las que no exista el Estado.

Se requiere definir una nueva relación entre Estado y mercado. Y el futuro de la centroizquierda en Chile está en construir un acuerdo sobre este tema con el propósito de generar bienes públicos de alta calidad para todos. EP 